\title{
APREENSÕES PERCEPTIVA E OPERATÓRIA EM QUESTÕES DA PRIMEIRA FASE DO NÍVEL 1 DA OBMEP
}

\author{
Juliana Gabriele Kiefer ${ }^{1}$; José Carlos Pinto Leivas ${ }^{2}$
}

\section{RESUMO}

O objetivo deste trabalho é identificar questões da fase 1, nível 1, da Olimpíada Brasileira de Matemática das Escolas Públicas (Obmep) que podem possibilitar a mobilização das apreensões perceptiva e operatória favorecendo, assim, a visualização em geometria. Cabe ressaltar que tal estudo justifica-se tendo em vista explorar tais questões com uma turma do $6^{\circ}$ ano do Ensino Fundamental, futuramente. Para tanto, adotam-se pressupostos teóricos dos registros de representação semiótica, no que tange aos registros figurais quanto às apreensões perceptiva e operatória, bem como procedimentos metodológicos da pesquisa de cunho qualitativo bibliográfico em que as fontes de produção de dados são provas da fase 1, nível 1 (correspondentes ao $6^{\circ}$ e $7^{\circ}$ ano do Ensino Fundamental) das edições de 2005 a 2019 da Obmep. Os resultados apontam variedade nas ações/modificações a serem realizadas nas figuras, sendo elas: sobreposição; justaposição; montagem; recortar e montar; dobrar; dobrar e recortar; planificar; girar/rotacionar.

Palavras-chave: Pesquisa Bibliográfica; Geometria; Apreensões figurais.

Eixo Temático: Educação, Cultura e Comunicação (ECC).

\section{INTRODUÇÃO}

O presente trabalho trata de uma investigação em andamento, constituída, inicialmente, na disciplina de Geometria: ensino e aprendizagem do Curso de Doutorado em Ensino de Ciências e Matemática da Universidade Franciscana. Cabe ressaltar que tal estudo justifica-se tendo em vista, futuramente, elaborar uma

\footnotetext{
${ }^{1}$ Doutoranda no Programa de Pós-graduação em Ensino de Ciências e Matemática - Universidade Franciscana - UFN. Bolsista da Coordenação de Aperfeiçoamento de Pessoal do Ensino Superior (CAPES). E-mail: juliana_kiefer@hotmail.com

${ }^{2}$ Docente no Programa de Pós-graduação em Ensino de Ciências e Matemática - Universidade Franciscana - UFN. E-mail: leivasjc@ufn.edu.br
} 
proposta de ensino envolvendo conceitos geométricos, visando o processo de visualização, a ser desenvolvida com estudantes do $6^{\circ}$ ano do Ensino Fundamental e buscando explorar diferentes recursos didáticos.

A Base Nacional Comum Curricular (BNCC) evidencia a importância de considerar o papel heurístico das experimentações na aprendizagem da Matemática (BRASIL, 2018). De modo específico, para a unidade temática da geometria, salienta que "[...] estudar posição e deslocamento no espaço, formas e relações entre elementos de figuras planas e espaciais pode desenvolver o pensamento geométrico" (BRASIL, 2018, p. 271).

Nesse sentido, Duval (2012, p. 118) destaca que "[...] diferentes tipos de operações visuais dão às figuras potencialidades heurísticas". Para Jahn e Bongiovanni (2019, p. 245), a " capacidade de modificar uma figura de partida para visualizar a resolução de um problema pode ser desenvolvida e deve ser estimulada pelo professor no ensino da Matemática, em particular na Geometria."

Assim, diante deste contexto, o objetivo deste trabalho é identificar questões da fase 1, nível 1 da Olimpíada Brasileira de Matemática das Escolas Públicas (Obmep) que podem possibilitar a mobilização das apreensões perceptiva e operatória, favorecendo, assim, a visualização em geometria. Tais aspectos teóricos mencionados serão explicitados na próxima seção.

\section{VISUALIZAÇÃO EM GEOMETRIA: RELAÇÕES ENTRE APREENSÃO PERCEPTIVA E OPERATÓRIA}

Para Duval (2012), figuras possibilitam diferentes interpretações, sendo assim denominadas de apreensões figurais: sequencial (relacionada com a construção ou descrição, cujo objetivo é a reprodução de uma figura); perceptiva; discursiva ${ }^{3}$ e operatória. Neste estudo, abordaremos de modo mais específico a perceptiva e a operatória.

\footnotetext{
3 “[...] corresponde a uma explicitação de outras propriedades matemáticas da figura, além daquelas indicadas por uma legenda ou pelas hipóteses do enunciado” (JAHN; BONGIOVANNI, 2019, p. 245).
} 
A apreensão perceptiva " [...] é aquela que permite identificar ou reconhecer imediatamente uma forma ou um objeto, no plano ou no espaço" (JAHN; BONGIOVANNI, 2019, p. 246) e a operatória "[...] corresponde a transformar modificar - a figura dada em outras figuras para obter novos elementos que poderão levar à ideia da solução de um problema ou de uma prova matemática." (p. 249).

De acordo com Moretti e Brandt (2013), as apreensões podem aparecer de forma articulada, dependendo do problema a ser resolvido. Assim, da conexão entre as apreensões perceptiva e operatória, resulta o processo de visualização.

\section{METODOLOGIA}

Os procedimentos metodológicos adotados neste estudo são de cunho qualitativo e caráter bibliográfico, pois utiliza material já elaborado para desenvolvê-lo (GIL, 2002). Ou seja, as fontes de produção de dados são as provas citadas anteriormente.

A Obmep é um projeto nacional dirigido às escolas públicas e privadas brasileiras, realizado pelo Instituto de Matemática Pura e Aplicada - IMPA, com o apoio da Sociedade Brasileira de Matemática - SBM, e promovida com recursos do Ministério da Educação e do Ministério da Ciência, Tecnologia, Inovações e Comunicações - MCTIC. Justifica-se o período de 2005 a 2019, pois se refere à primeira e última edição, respectivamente, em que foi possível acessar as provas a partir do site da Obmep".

Após selecionar as provas, foram identificadas as questões que contemplavam os seguintes critérios:

1) apresentam o registro figural no enunciado;

2) apresentam determinados tipos de ações/modificações nas figuras, seja no enunciado da questão e/ou necessários para a solução.

\footnotetext{
${ }^{4}$ http://www.obmep.org.br
} 


\section{RESULTADOS E DISCUSSÕES}

Na Figura 1, apresenta-se oito tipos de ações/modificações identificadas nas provas da fase 1, Nível 1, distribuídas conforme as edições de 2005 a 2019.

Figura 1: Dados coletados.

\begin{tabular}{|c|c|c|c|c|c|c|c|c|c|c|c|c|c|c|c|c|}
\hline AÇÄO/MODIFICAÇÃO & 2005 & 2006 & 2007 & 2008 & 2009 & \begin{tabular}{|l|}
2010 \\
\end{tabular} & 2011 & 2012 & 2013 & 2014 & 2015 & 2016 & 2017 & 2018 & 2019 & TOTAL \\
\hline Justapor & Q5 & & & Q12; Q14 & & & & & & & Q3 & & Q8 & & & 5 \\
\hline Sobrepor & & Q4 & & & & & Q11 & & & & & Q2 & & & & 3 \\
\hline Dobrar & & & Q10 & Q11 & & & & Q4 & & & Q18 & Q11 & & & Q20 & 6 \\
\hline Dobrar e recortar & & & & & & Q8 & & Q10; Q14 & & & & Q9 & & & Q13 & 5 \\
\hline Montar & & & & & Q15 & Q12 & & & & Q3 & & & & & & 3 \\
\hline Recortar e montar & & & Q16 & & & Q7 & & & & & & & & & & 2 \\
\hline Girar/rotacionar & & & & & & & Q8 & Q9 & & & & Q6 & Q17 & & Q9 & 5 \\
\hline Planificar & & Q17 & & Q6 & & & Q19 & Q8 & & & & & Q13 & & & 5 \\
\hline TOTAL & 1 & 2 & 2 & 4 & 1 & 3 & 3 & 5 & 0 & 1 & 2 & 4 & 3 & 0 & 3 & 34 \\
\hline
\end{tabular}

Fonte: Dados da pesquisa.

As questões que requerem ações/modificações de "justapor" são, em sua maioria, aquelas que envolvem o encaixe de peças. Já as de "sobrepor", envolvem a ordem em que foram colocados discos na mesa, ou entrelace de anéis e cartões de cartolina sobrepostos, por exemplo.

As de "dobrar" requerem, também, o cálculo das medidas de algumas grandezas associadas às figuras, como área ou comprimento. Já as que envolvem além das dobras, também o recorte, em sua maioria, requerem como solução a representação figural obtida ao realizar o processo inverso de desdobrar.

A maioria das questões que envolvem o "montar", relacionam diferentes formas de compor uma figura a partir de subfiguras dadas. As de "recortar e montar", requerem, também, o cálculo de algumas das medidas das grandezas associadas como comprimento ou área. As de "girar/rotacionar", bem como as de "planificar", envolvem, em sua maioria, a representação figural do cubo.

Observa-se que, em todas as edições, com exceção de 2013 e 2018, foram identificadas questões que pudessem privilegiar a mobilização das apreensões perceptiva e operatória, conforme os critérios de seleção adotados. Pode ser que 
outras questões também explorem essas apreensões, sem considerar os critérios adotados ou que, ainda, explorem as outras apreensões, além dessas.

De todas as edições, a do ano de 2012 foi a que mais privilegiou as ações/modificações nas figuras, sendo identificadas questões que abordaram dobras, dobras e recortes, bem como girar/rotacionar e planificar. Além disso, a ação de dobrar foi a mais privilegiada em todas as edições, sendo identificada em 11 questões, em que cinco delas ainda envolvendo a ação de recorte. Na Figura 2, mostra-se um exemplo.

Figura 2: Exemplo de questão que envolve a ação de "dobrar e recortar"

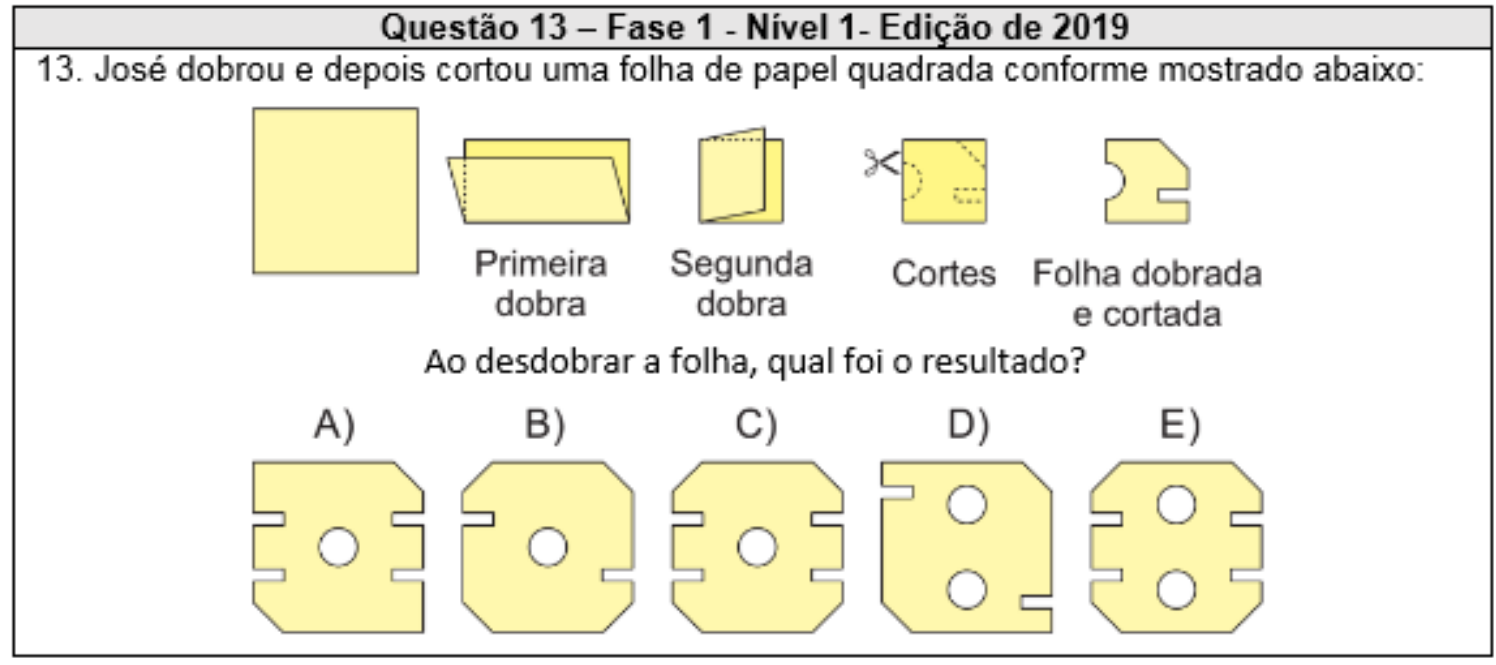

Fonte: Organizado pelos autores a partir do banco de provas da Obmep (2019).

Nessa questão, utiliza-se um recurso didático simples, ou seja, uma folha de papel e tesoura. Entretanto, o estudante não dispõe destes recursos para fazê-lo passo a passo no momento da prova. Assim, precisa mobilizar as apreensões perceptivas e operatórias a fim de visualizar a solução. O enunciado da questão é dado em língua natural e em figural, sendo que são realizadas ações de dobrar e de recortar. Para solucionar a questão, é necessário que o estudante realize tratamentos figurais de desdobrar a folha e perceber qual resultado é obtido. 


\section{CONCLUSÃO}

O estudo realizado identificou 34 questões da fase 1, nível 1 da Olimpíada Brasileira de Matemática das Escolas Públicas (Obmep) nas edições de 2005 a 2019, as quais possibilitam a mobilização das apreensões perceptiva e operatória favorecendo, assim, a visualização em geometria. As ações/modificações nas figuras, seja no enunciado e/ou necessária para a solução que apareceram com mais frequência, foram o de "dobrar", "justapor", "dobrar e recortar", "girar/rotacionar" e "planificar". A partir disso, observa-se que, além de envolverem as apreensões perceptiva e operatória nas questões, estas, ainda, apresentam-se de modo variado.

Assim, tendo em vista os resultados obtidos, verifica-se grande possibilidade de adaptar ou até mesmo elaborar questões próximas às identificadas para a composição da sequência de ensino a ser organizada e desenvolvida nos anos finais do Ensino Fundamental. Cabe ressaltar ainda, a possibilidade de utilizar recursos didáticos como, por exemplo, papel, cartolina, dados, discos, anéis, entre outros.

\section{AGRADECIMENTOS}

A Coordenação de Aperfeiçoamento de Pessoal do Ensino Superior (CAPES).

\section{REFERÊNCIAS}

BRASIL, MEC. Base Nacional Comum Curricular. Brasília, 2018.

DUVAL, R. Abordagem cognitiva de problemas de geometria em termos de congruência. Trad. Méricles T. Moretti. REVEMAT, v.7, n.1, Florianópolis: UFSC/MTM/PPGECT, 2012B. (Disponível em http://www.periodicos.ufsc.br/index.php/revemat).

GIL, A. C. Como elaborar projetos de pesquisa. São Paulo: Atlas, 2002 
JAHN, A.P; BONGIOVANNI, V. Apreensão Operatória de Figuras em Situações Geométricas. JIEEM, v.12, n.3, p. 245-257, 2019.

MORETTI, Méricles Tadeu, BRANDT, Celia Fink. A Confluência de Ideias para Criar um Espaço de aprendizagem em Geometria, 2013. (Disponível em http://www4.pucsp.br/lllpesquisaedmat/download/resumos/GD10-Geo-mericles-celia -fim.pdf 